\title{
Quiste de duplicación intestinal en el piso de la boca
}

\section{Foregut Duplication Cyst of the Floor of Mouth}

\author{
Guillermina Thevenón ${ }^{1}$ Martín Sabas ${ }^{1}$ Claudio Milicchio $^{1}$ Diego Quirós ${ }^{1}$
} ${ }^{1}$ Servicio de Diagnóstico por Imágenes, Imágenes MDQ, Mar del
Plata, Buenos Aires, Argentina

Rev Argent Radiol 2019;83:124-126.

Estimados Editores,

Los quistes de duplicación intestinal son lesiones que presentan la mucosa del sistema digestivo con paredes de músculo liso, en localización anormal y que constituyen una anomalía congénita poco frecuente. ${ }^{1,2}$

Presentamos el caso de una niña de tres años con un cuadro de repercusión general asociado a odinodisfagia de 48 horas de evolución. En el examen físico, presentaba abombamiento del piso de la boca con lateralización de la base de la lengua hacia la derecha. Inicialmente se realizó una ecografía de cuello, en la que se identificaron adenopatías latero-cervicales izquierdas. Se sugirió la internación y se realizaron estudios de laboratorio que no presentaron alteraciones. Se indicó una resonancia magnética de cuello con contraste endovenoso bajo sedación, en la que se observó, a nivel del piso de la boca, una imagen quística biloculada y heterogénea, predominantemente
Address for correspondence Guillermina Thevenón, MD, Servicio de Diagnóstico por Imágenes, Imágenes MDQ, Mar del Plata, Buenos Aires, Argentina (e-mail: guillerminathevenon@gmail.com).

hiperintensa en secuencias ponderadas en $\mathrm{T} 1 \mathrm{y} \mathrm{T} 2$, con realce periférico tras la administración del contraste endovenoso, que no presentó restricción en secuencias de difusión (-Figs. 1 y 2).

Dada la presentación aguda del cuadro, se decidió realizar una marsupialización quirúrgica de la tumoración quística, que mostró contenido líquido denso, turbio y mucoso (-Fig. 3). Se remitieron muestras al servicio de anatomopatología, que informó la presencia de un quiste de duplicación intestinal con mucosa colónica heterotópica. La paciente fue reintervenida para la extirpación completa de la lesión, con evolución satisfactoria y sin complicaciones.

Los quistes de duplicación intestinal pueden presentarse desde la cavidad oral hasta el recto, siendo su localización más frecuente el íleon en un 40\%, luego el esófago, el colon, el yeyuno, el estómago, el duodeno y el recto. ${ }^{1,3}$ La localización

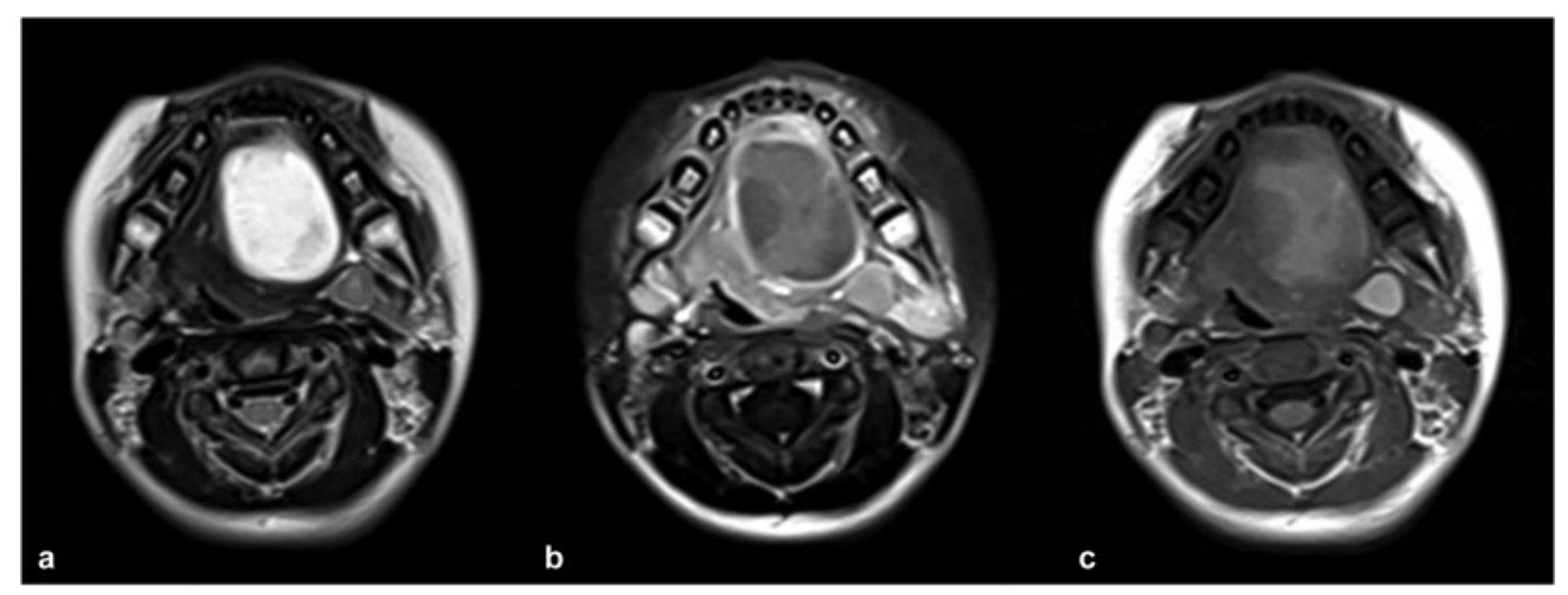

Fig. 1 Resonancia magnética en cortes axiales, secuencias ponderadas en T2 (a), T1 con saturación grasa y contraste endovenoso (b) y T1 (c). Se observa una imagen quística biloculada, heterogénea, con refuerzo periférico tras la administración del contraste endovenoso, ubicada en el piso de la boca.

received

November 15, 2017

accepted

January 28, 2019
DOI https://doi.org/

10.1055/s-0039-1683424. ISSN 1852-9992.
Copyright (e) 2019, Sociedad Argentina de Radiología. Publicado por Thieme Revinter Publicações Ltda., Rio de Janeiro, Brazil. Todos los derechos reservados.

\section{License terms}

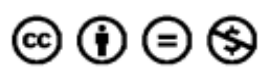




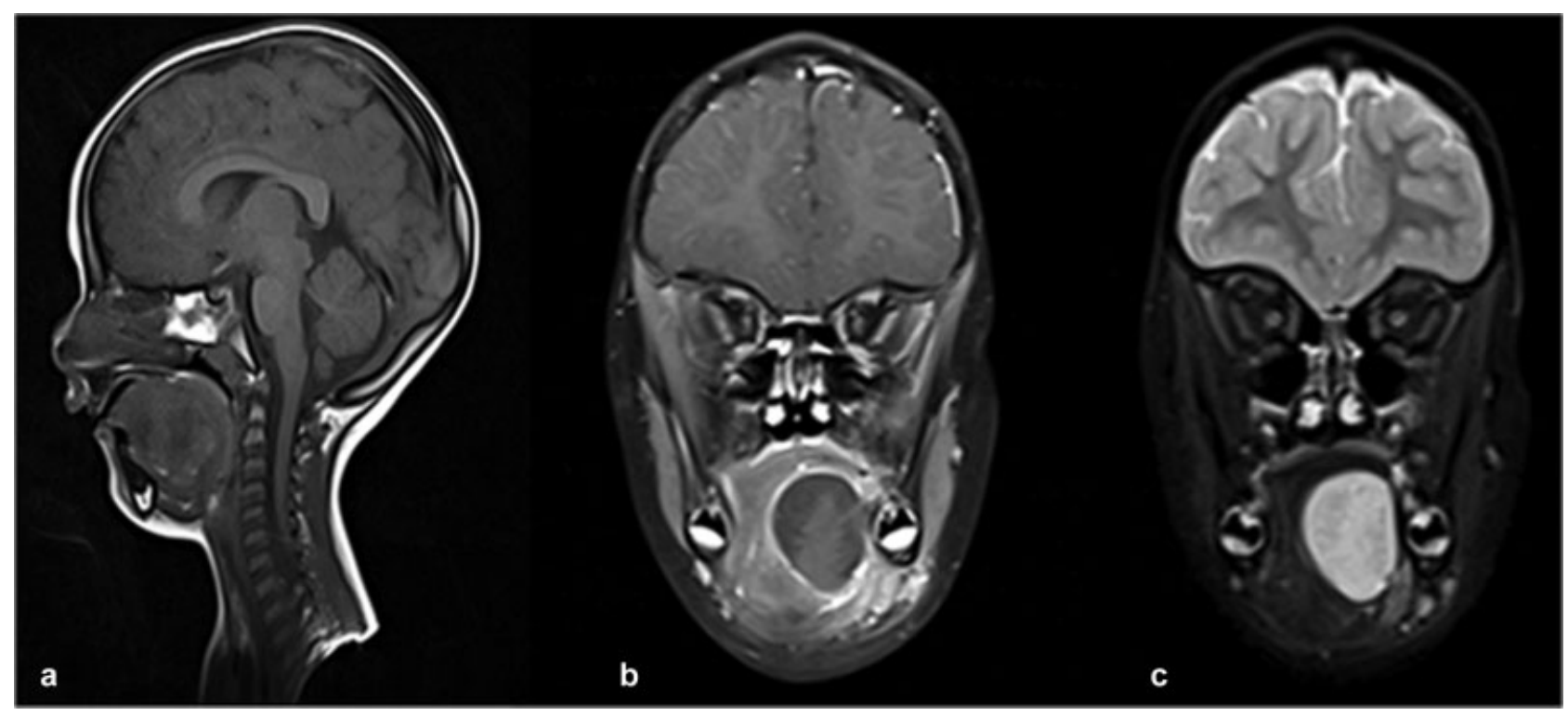

Fig. 2 Resonancia magnética en corte sagital en secuencia ponderada en T1 (a) y cortes coronales en secuencias ponderadas en T1 con saturación grasa y contraste endovenoso (b) y T2 con saturación grasa (c). Se observa la imagen quística comprometiendo base de la lengua y piso de la boca.

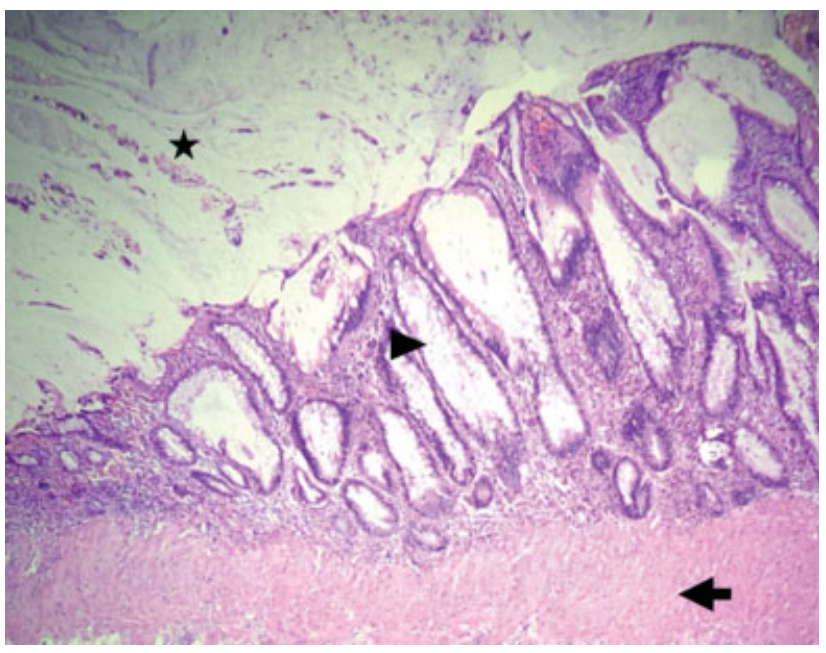

Fig. 3 Histología de la pieza quirúrgica (tinción $\mathrm{H}-\mathrm{E}$ ). Se observa una capa basal de músculo liso (flecha), capa mucosa con glándulas colónicas (cabeza de flecha) y la luz de la cavidad (estrella).

en la base de la lengua representa una frecuencia del 0,3\% de los casos y es más frecuente en niños que en niñas. ${ }^{4}$ Se pueden presentar como duplicaciones únicas o múltiples hasta en el $15 \%$ de los casos. $^{5}$ En cuanto a su morfología, pueden ser diverticulares, quísticos o tubulares y estar unidos o no a la vía digestiva. La mucosa que los recubre generalmente es igual al sector de intestino adyacente, aunque también se reportan casos en que pueden contener tejido ectópico, en particular de tipo gástrico o pancreático. ${ }^{1}$

Los quistes de duplicación intestinal pueden tener una presentación clínica variable, con un amplio espectro de signos y síntomas de acuerdo a su localización. 1,6 Aquellos localizados en el piso de la boca pueden presentar cuadros de dificultad respiratoria, alteración de la deglución, sangrados recurrentes o secreción pardusca de un seno lingual. ${ }^{2,7}$
Frente a una lesión en el piso de la boca, los diagnósticos diferenciales iniciales suelen ser, por frecuencia, ránula, linfangioma, hemangioma, quiste dermoide, quiste del conducto tirogloso, mucocele, quiste linfoepitelial, higromas quísticos o coristoma lingual. ${ }^{8}$

Una vez diagnosticadas, las duplicaciones intestinales deben recibir tratamiento quirúrgico, ya que presentan potencial de malignización en la edad adulta. ${ }^{5}$

\section{Confidencialidad de los datos}

Los autores declaran que han seguido los protocolos de su centro de trabajo sobre la publicación de datos de pacientes, y que todos los pacientes incluidos en el estudio han recibido información suficiente y han dado su consentimiento informado por escrito para participar en dicho estudio.

\section{Financiación}

Imágenes MDQ.

\section{Conflicto de intereses}

Los autores declaran no tener ningún conflicto de intereses.

\section{Agradecimientos}

A la Dra. Juana Ross, del servicio de diagnóstico por imágenes de la Clínica Colón, Mar del Plata.

\section{Bibliografía}

1 Marcpherson RI. Gastrointestinal tract duplications: clinical, pathologic, etiologic, and radiologic considerations. Radiographics 1993;13(5):1063-1080

2 Tong SC, Pitman M, Anupindi SA. Best cases from the AFIP. Ileocecal enteric duplication cyst: radiologic-pathologic correlation. Radiographics 2002;22(5):1217-1222 
3 Chuquisana-Mostacero C, Enríquez de Salamanca-Celada J, Azorín-Cuadrillero D. Dos casos de quiste de intestino anterior en cavidad oral. Cir Plást Iberolatinoam 2017;43(2):179-185

4 Milán-Montenegro JG, Jaramillo-Rodríguez Y, Nares-Cisnerosc J, Guerrero-Sepúlveda J. Duplicación del tubo digestivo manifestada como quiste lingual. Caso clínico y revisión de la literatura. Bol Méd Hosp Infant México 2014;71(3):163-166

5 Letelier A, Barria C, Beltrán M, Moreno C. Duplicación intestinal: Diagnóstico y tratamiento de una condición inusual. Rev Chil Cir 2009;61(2):171-175
6 Stock F, Cammarata-Scalisi F, Petrosino P, Arenas de Sotolongo A, Milano M, Farias M. Duplicación gástrica. Reporte de un caso y revisión de la literatura. Acta Gastroenterol Latinoam 2010;40(3): 258-263

7 Hambarde S, Bendre P, Taide D. Foregut duplication cyst presenting as lingual swelling: Case report and review of literature. Natl J Maxillofac Surg 2011;2(1):2-5

8 Lister J, Zachary RB. Cystic duplications in the tongue. J Pediatr Surg 1968;3(4):491-493 